\title{
Immunoglobulin G4-Related Disease Masquerading an Epidural Spinal Cord Tumor
}

\author{
Ebtesam Abdulla ${ }^{1}$ Harleen Luther ${ }^{1}$ Tejal Shah ${ }^{2}$ Nisha Chandran ${ }^{3}$ \\ ${ }^{1}$ Department of Neurosurgery, Salmaniya Medical Complex, \\ Manama, Bahrain \\ 2Department of Radiology, Salmaniya Medical Complex, Manama, \\ Bahrain \\ ${ }^{3}$ Department of Anatomical Pathology, Salmaniya Medical Complex, \\ Manama, Bahrain

\begin{abstract}
Address for correspondence Ebtesam Abdulla, BMedSc, MD, Department of Neurosurgery, Salmaniya Medical Complex, Manama, Bahrain (e-mail: Dr.Ebtesam@hotmail.com).
\end{abstract} \\ J Neurosci Rural Pract 2021;12:424-426.
}

\author{
Abstract \\ Keywords \\ - immunoglobulin G4 \\ - paraplegia \\ - spinal cord \\ compression
}

Background Immunoglobulin G4-related disease (IgG4-RD) is a recently identified multisystemic fibroinflammatory condition of unclear etiology. IgG4-RD of the epidural tissue causing spinal cord compression is extremely rare.

Case description Here, we present a 27 -year-old male with epidural mass, causing spinal cord compression at the level of D5-D6. The mass proved pathologically to be epidural inflammatory pseudotumor (IPT) related to IgG4. Spinal decompression was done. The patient was started on steroid treatment and reported a complete resolution of his symptoms over a 3 years' follow-up period.

Conclusion To the authors' knowledge, this is the first case of IgG4-related epidural IPT and spinal cord compression in Bahrain and the Middle East. IgG4-RD should always be considered as a part of the differential diagnosis of spinal tumors.

\section{Introduction}

Immunoglobulin G4-related disease (IgG4-RD) is a recently identified multisystemic fibroinflammatory condition of unclear etiology. ${ }^{1,2}$ It usually involves the pancreas, hepatobiliary tract, lungs, salivary gland, orbit, and lymph nodes. ${ }^{1-4}$ Spinal epidural tissue involvement is extremely rare. ${ }^{1,3-6}$ This report aims to present a rare case occurrence of IgG4-related epidural inflammatory pseudotumor (IPT), causing compression on the spinal cord in a young male with a relevant literature review.

\section{Case Description}

A 27-year-old male with an 8-day history of back pain and progressive numbness and weakness in both lower

published online March 15, 2021
DOI https://doi.org/

10.1055/s-0041-1722841 ISSN 0976-3147. limbs was admitted without any previous traumatic spinal injury. The patient denied fever or fecal and urine incontinence. The vital signs were normal, and the patient was fully awake. Neurological evaluation revealed paraparesis (Grade 3/5 Medical Research Council) and bilateral leg hypoesthesia. Bilaterally, there was an acceleration of knee and ankle reflexes and positive Babinski signs.

All laboratory investigations were within normal limits, as were the findings on chest radiography. Cervicothoracic magnetic resonance imaging (MRI) demonstrated a posterior, expansile, epidural mass from D5 to D6, causing spinal cord compression. The mass displayed isointensity in the T1-weighted sequence (- Fig. 1A), heterogeneous hyperintensity in the T2-weighted sequence ( - Fig. 1B), and homogenous enhancement in postcontrast $\mathrm{T} 1$-weighted sequence (-Fig. 1C). No bone marrow abnormality in the vertebrae, (c) 2021. Association for Helping Neurosurgical Sick People.

This is an open access article published by Thieme under the terms of the Creative Commons Attribution-NonDerivative-NonCommercial-License, permitting copying and reproduction so long as the original work is given appropriate credit. Contents may not be used for commercial purposes, or adapted, remixed, transformed or built upon. (https://creativecommons.org/licenses/by-nc-nd/4.0/).

Thieme Medical and Scientific Publishers Pvt. Ltd. A-12, 2nd Floor, Sector 2, Noida-201301 UP, India 


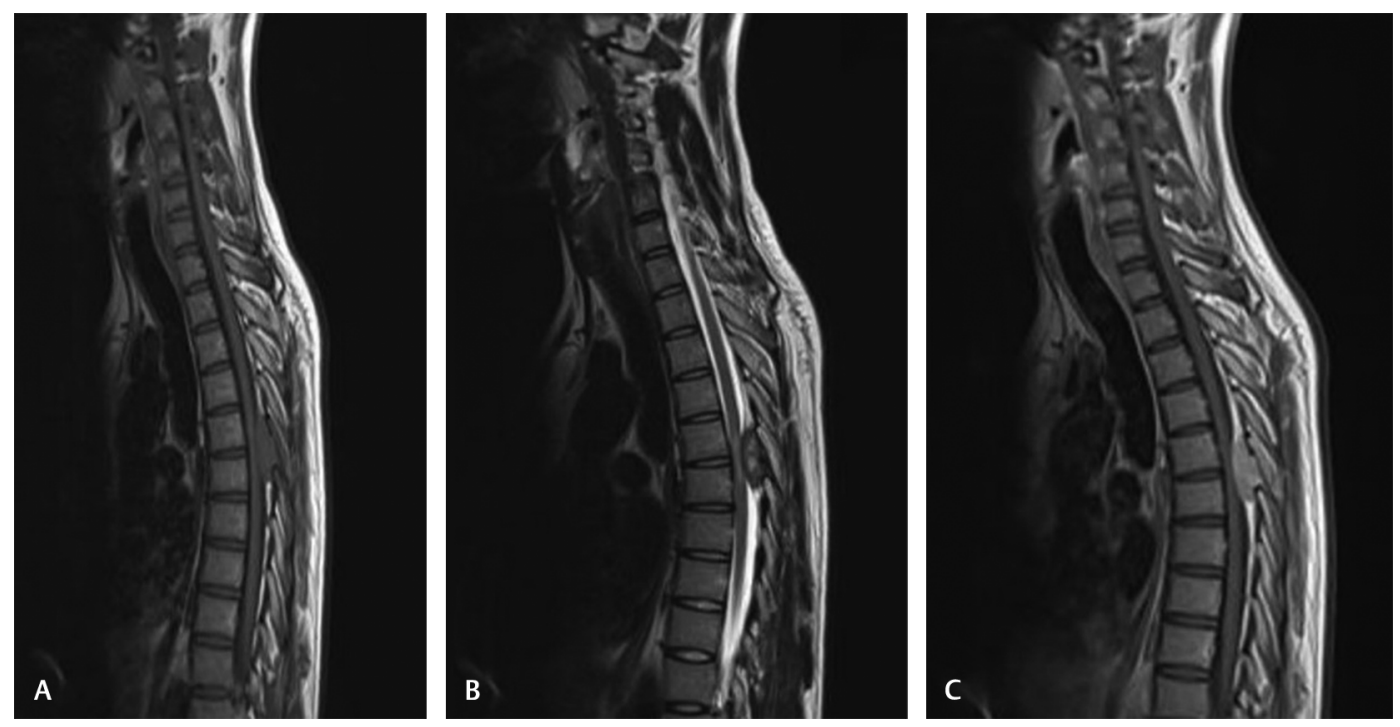

Fig. 1 Cervicothoracic magnetic resonance imaging demonstrates an expansile epidural mass from D5 to D6. The mass shows isointensity on the sagittal T1-weighted image sequence (A), heterogeneous hyperintensity on the sagittal T2-weighted sequence (B), and homogenous enhancement in the postcontrast T1-weighted image (C) with spinal cord compression.

adjacent bony destruction, or bony sclerosis was seen on MRI. The whole-body positron emission tomography scan revealed no signs of malignancy or abnormality in the spleen, liver, pancreas, adrenal, or salivary glands. The differential diagnosis entertained was spinal epidural tumors, such as lymphoma, plasmacytoma, or metastases.

The patient underwent a decompressive laminectomy of the D5-D6 vertebrae with excision of the compressive mass lesion. The mass was hard, grayish-white, located inside the epidural space below the ligamentum flavum, and attached to the thecal sac at its midlevel. After removing the mass, we sutured the dural defect using a fascial flap. A diagnosis of epidural IPT related to IgG4 was obtained by histopathology ( - Fig. 2). The resected mass revealed abundant lymphoplasmacytic infiltrates and radiating collagen fibrosis with no evidence of neoplastic cells. The results of mycobacterial and fungal staining and cultures were all negative. The lymphoma panel was negative. Several IgG4 positive plasma cells, greater than 50 /high power field, IgG4+/IgG+ plasma cell percentage $>50 \%$, were found in the IgG4 immunohistochemistry analysis. Elastic staining revealed obliterative phlebitis. The patient's serum IgG4 level $(0.70 \mathrm{~g} / \mathrm{L})$ was within normal limits. The patient was started on steroid treatment and reported a complete resolution of his symptoms over a 3 years' follow-up period.

\section{Discussion}

IgG4-RD is a rare, potentially underdiagnosed cause of pseudotumor-like lesions. ${ }^{1-6}$ The condition is defined by fibrosis induced by IgG4+ plasma cells, which may ultimately contribute to end-organ failure. ${ }^{2}$ IgG4-RD manifests predominately in the pituitary gland, brain parenchyma, meninges,
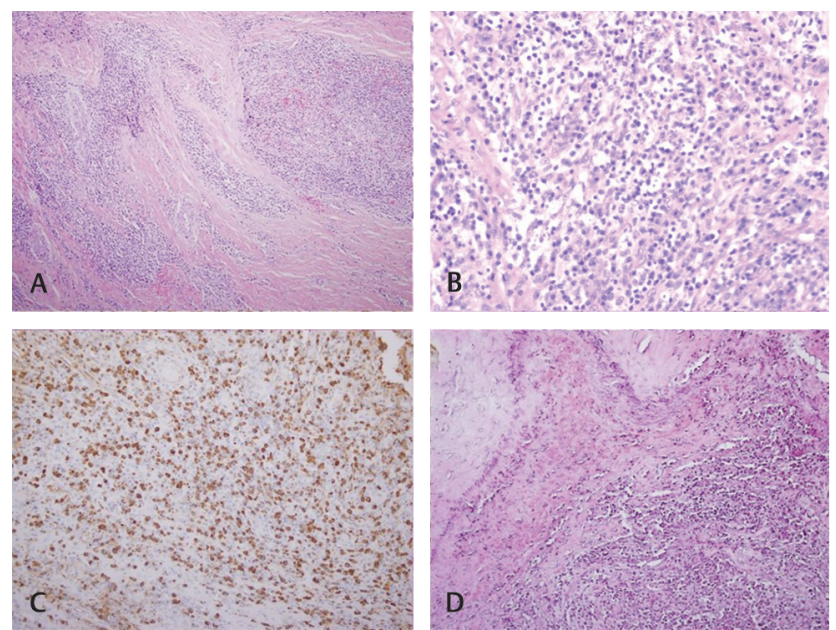

Fig. 2 The epidural mass histopathology. Fibrocollagenous tissue with inflammatory nodules infiltrates rich in plasma cells, lymphocytes, and several histiocytes, hematoxylin and eosin, 10X, and 40x (A, B). Immunohistochemistry of immunoglobulin G4+ (IgG4+) plasma cells with a gross cellularity of more than $50 /$ high-power field and an $\mathrm{lgG} 4 / \mathrm{lgG}$ ratio of more than $50 \%$ (C). Obliterative phlebitis is seen on elastic stain 20X (D).

peripheral nerves, and rarely less often epidural tissue in the central nervous system. ${ }^{2-6}$

IgG4-related epidural IPT may present with varied symptoms depending upon how severe the compression is and on the segment of the spinal cord affected. ${ }^{3,5}$ In the case discussed here, the patient stated back pain that eventually led to paraparesis and bilateral leg hypoesthesia.

IgG4-related epidural IPT is often challenging to diagnose because clinical data and imaging are usually 
Table 1 Characteristics of cases of IgG4-related epidural IPT causing spinal cord compression reported in the literature

\begin{tabular}{|l|l|l|l|l|l|l|l|}
\hline Source & $\begin{array}{l}\text { Age(y)/ } \\
\text { sex }\end{array}$ & Location & $\begin{array}{l}\text { Bony } \\
\text { destruction }\end{array}$ & $\begin{array}{l}\text { Contrast- } \\
\text { enhancement }\end{array}$ & $\begin{array}{l}\text { Serum IgG4 } \\
\text { (g/dL) }\end{array}$ & Management & Outcome \\
\hline Ferreira et al $2016^{5}$ & $57 / F$ & D10-D12 & No & Well & 0.662 & $\begin{array}{l}\text { Surgery, } \\
\text { steroids }\end{array}$ & Improvement \\
\hline Williams et al $2017^{4}$ & $46 / \mathrm{F}$ & C4-T1 & No & Well & 0.38 & $\begin{array}{l}\text { Biopsy, } \\
\text { steroids, } \\
\text { azathioprine }\end{array}$ \\
improvement \\
\hline Rumalla et al $2017^{1}$ & 50/M & T5-T6 & Yes & Well & Normal & $\begin{array}{l}\text { Surgery, } \\
\text { steroids }\end{array}$ & $\begin{array}{l}\text { Complete } \\
\text { resolution }\end{array}$ \\
\hline Winkel et al $2018^{6}$ & $48 / \mathrm{F}$ & L2-L3 & No & Well & Normal & $\begin{array}{l}\text { Surgery, } \\
\text { steroids }\end{array}$ & $\begin{array}{l}\text { Complete } \\
\text { resolution }\end{array}$ \\
\hline Merza et al $2019^{3}$ & 60/F & T4-T5 & No & Well & 2.07 & $\begin{array}{l}\text { LP, surgery, } \\
\text { steroids }\end{array}$ & $\begin{array}{l}\text { Complete } \\
\text { resolution }\end{array}$ \\
\hline Our case 2020 & 27/M & D5-D6 & No & Well & 0.70 & $\begin{array}{l}\text { Surgery, } \\
\text { steroids }\end{array}$ & $\begin{array}{l}\text { Complete } \\
\text { resolution }\end{array}$ \\
\hline
\end{tabular}

Abbreviations: IgG4, immunoglobulin G4; LP, IPT, inflammatory pseudotumor; lumbar puncture.

nonspecific. It often appears as a well-enhanced extradural mass on computed tomography or MRI that does not point to a specific diagnosis. ${ }^{1,3-6}$ Therefore, the diagnosis of IgG4-RD is based primarily on the pathological evaluation of the surgical specimen. ${ }^{1-6}$ The key pathological features recognized in IgG4 lesions are lymphoplasmacytic infiltrate, storiform fibrosis, and obliterative phlebitis. ${ }^{1-6}$ Other possible findings are an increased serum IgG4 levels, an IgG4/IgG proportion greater than $40 \%$, and IgG4+ plasma cells infiltration of organs. ${ }^{1-6}$ However, the sensitivity and specificity of serum IgG4 in the diagnosis of IgG4-RD are uncertain. ${ }^{1}$

Steroid administration is the mainstay treatment for IgG4-RD and leads to a dramatic clinical response in most cases. ${ }^{1-6}$ For patients with motor function deficits or progressive neurological symptoms, spinal decompression is usually recommended. ${ }^{6}$ Steroid-sparing agents have also been used in patients with recurrent or refractory disease. ${ }^{1,2}$

We utilized the PubMed database to identify five cases (2000-2020) of IgG4-related epidural IPT causing spinal cord compression (- Table 1). Counting our case, patients averaged 48 years of age with a female predilection. Thoracic spine involvement was most common, followed by the cervicothoracic junction and lumbar spine (ratio $4: 1: 1)$. Serum IgG4 was normal in five of six cases (83.3\%). All lesions showed vivid contrast enhancement on MRI. Only one lesion caused bony destruction (16.6\%). Lesion biopsy, lumbar puncture for cerebrospinal fluid cytology analysis, and MRI were included as diagnostic modalities. Spinal decompression, steroid administration, and immunosuppressive therapy are among the management choices. All cases reported recorded symptomatic relief, with four cases at the final follow-up reporting complete symptoms resolution.

\section{Conclusion}

Given the rare incidence of IgG4-related epidural IPT, it is necessary to bear in mind the clinical suspicion of the disease so that the treatment can begin at the optimal timing. While steroid is the mainstay of treatment, spinal decompression may be needed to alleviate spinal cord compression.

\section{Authors' Contributions}

All authors greatly contributed to the conception, analysis, and interpretation of data. The article was critically revised by all authors for relevant intellectual content and the manuscript version to be published was finally accepted.

\section{Conflict of Interest}

None declared.

\section{References}

1 Rumalla K, Smith KA, Arnold PM. Immunoglobulin G4-related epidural inflammatory pseudotumor presenting with pulmonary complications and spinal cord compression: case report. J Neurosurg Spine 2017;26(6):688-693

2 Della-Torre E, Lanzillotta M, Doglioni C. Immunology of IgG4-related disease. Clin Exp Immunol 2015;181(2):191-206

3 Merza N, Taha A, Lung J, Benderman AW, Wright SE. IgG4-related sclerosing disease causing spinal cord compression: the first reported case in literature. Case Reports Immunol 2019;2019:3618510

4 Williams MM, Mashaly H, Puduvalli VK, Jin M, Mendel E. Immunoglobulin G4-related disease mimicking an epidural spinal cord tumor: case report. J Neurosurg Spine 2017;26(1):76-80

5 Ferreira NR, Vaz R, Carmona S, et al. IgG4-related disease presenting with an epidural inflammatory pseudotumor: a case report. J Med Case Reports 2016;10:61

6 Winkel M, Lawton CD, Sanusi OR, Horbinski CM, Dahdaleh NS, Smith ZA. Neuro-surgical considerations for treating IgG4-related disease with rare spinal epidural compression. Surg Neurol Int 2018;9:209 